\title{
Percutaneous Transluminal Septal Myocardial Ablation to a Pre-Procedural Coronary Computed Tomography Angiography-Detected Anomalous Septal Branch
}

Eri Nakai, MD; Yasuhiro Hamatani, MD; Takuya Hasegawa, MD, PhD;

Tatsuya Nishii, MD, PhD; Atsushi K. Kono, MD, PhD; Yuta Kato, MD, PhD;

Muneyuki Kadota, MD, PhD; Masashi Amano, MD; Atsushi Okada, MD, PhD;

Hiroyuki Takahama, MD, PhD; Makoto Amaki, MD, PhD; Tetsuya Fukuda, MD, PhD;

Hideaki Kanzaki, MD, PhD; Satoshi Yasuda, MD, PhD; Chisato Izumi, MD, PhD

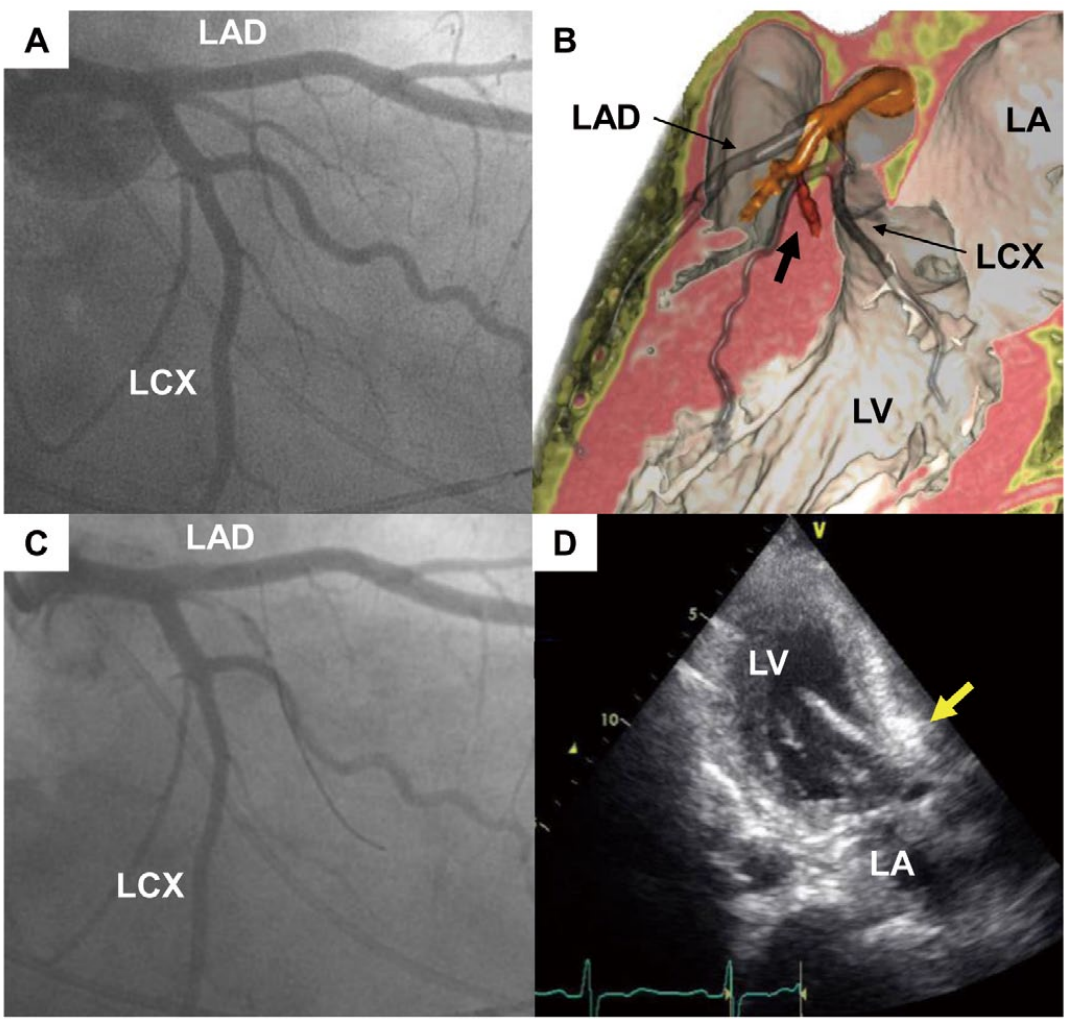

Figure. (A) Coronary angiography (right anterior oblique caudal view). (B) Three-dimensional image created from computed tomography data. Black arrow, anomalous septal branch. (C) Inflation of an over-the-wire balloon in the target anomalous septal branch. (D) Transthoracic echocardiography at percutaneous transluminal septal myocardial ablation. The basal septum was selectively enhanced (yellow arrow). LA, left atrium; LAD, left anterior descending artery; LCX, left circumflex artery; LV, left ventricle.

Received August 6, 2019; revised manuscript received August 13, 2019; accepted August 20, 2019; J-STAGE Advance Publication released online September 14, 2019 Time for primary review: 1 day

Department of Cardiovascular Medicine (E.N., Y.H., T.H., Y.K., M.K., M. Amano, A.O., H.T., M. Amaki, H.K., S.Y., C.I.), Department of Radiology (T.N., A.K.K., T.F.), National Cerebral and Cardiovascular Center, Suita, Japan

S.Y. is a member of Circulation Reports' Editorial Team.

Mailing address: Yasuhiro Hamatani, MD, Department of Cardiovascular Medicine, National Cerebral and Cardiovascular Center, 6-1 Kishibe-Shimmachi, Suita 564-8565, Japan. E-mail: y.hamatani1114@gmail.com

ISSN-2434-0790 All rights are reserved to the Japanese Circulation Society. For permissions, please e-mail: cr@j-circ.or.jp 
7 he anatomy of the septal branch varies among patients and identification of the target branch is important for evaluating the feasibility of percutaneous transluminal septal myocardial ablation (PTSMA).

A 61-year-old hypertrophic cardiomyopathy man with drug-refractory symptoms was referred to the present institution. Transthoracic echocardiogram showed a maximum pressure gradient of $80 \mathrm{mmHg}$ across the left ventricular outflow tract (LVOT). Coronary angiography indicated a few septal branches applicable to PTSMA from the left anterior descending artery (Figure A). Meanwhile, coronary computed tomography angiography (CTA) unexpectedly but clearly showed that an anomalous septal branch at the bifurcation of the left main artery supplied the basal septum (Figure B).
At PTSMA, a total of $2.0 \mathrm{~mL}$ ethanol was injected into the target anomalous septal branch (Figure C,D). LVOT pressure gradient decreased from $50 \mathrm{mmHg}$ to $10 \mathrm{mmHg}$ after PTSMA to the anomalous septal branch. Postprocedural echocardiogram demonstrated a pressure gradient of $14 \mathrm{mmHg}$ without any complication. The patient was asymptomatic on exertion in the outpatient clinic.

Coronary CTA enables identification of the target branches, including any anomalous branches. In this case, we could not find the target anomalous septal branch until coronary CTA was done, suggesting the utility of coronary CTA for evaluating target branches before PTSMA.

\section{Disclosures}

S.Y. is a member of Circulation Reports' Editorial Team. 